\title{
Association between Dietary Inflammatory Index, Dietary Patterns, Plant-Based Dietary Index and the Risk of Obesity
}

\author{
Yoko B. Wang ${ }^{1,2} \mathbb{D}$, Nitin Shivappa ${ }^{3,4}$, James R. Hébert ${ }^{3,4}$, Amanda J. Page ${ }^{1,2} \mathbb{D}$, Tiffany K. Gill ${ }^{5}$ and \\ Yohannes Adama Melaku 2,5,6,*(D)
}

1 Vagal Afferent Research Group, Adelaide Medical School, University of Adelaide, Adelaide, SA 5000, Australia; yokobrigitte.wang@adelaide.edu.au (Y.B.W.); amanda.page@adelaide.edu.au (A.J.P.)

2 Nutrition, Diabetes \& Gut Health, Lifelong Health Theme, South Australian Health and Medical Research Institute (SAHMRI), Adelaide, SA 5000, Australia

3 Cancer Prevention and Control Program, University of South Carolina, Columbia, SC 29208, USA; shivappa@email.sc.edu (N.S.); jhebert@mailbox.sc.edu (J.R.H.)

4 Department of Epidemiology and Biostatistics, Arnold School of Public Health, University of South Carolina, Columbia, SC 29208, USA

5 Adelaide Medical School, University of Adelaide, Adelaide, SA 5000, Australia; tiffany.gill@adelaide.edu.au

6 Adelaide Institute for Sleep Health, College of Medicine and Public Health, Flinders University, Bedford Park, SA 5042, Australia

* Correspondence: yohannes.melaku@flinders.edu.au; Tel.: +61-87421946

Citation: Wang, Y.B.; Shivappa, N.; Hébert, J.R.; Page, A.J.; Gill, T.K.;

Melaku, Y.A. Association between Dietary Inflammatory Index, Dietary Patterns, Plant-Based Dietary Index and the Risk of Obesity. Nutrients 2021, 13, 1536. https://doi.org/ $10.3390 /$ nu13051536

Academic Editor: Jose Lara

Received: 10 March 2021

Accepted: 27 April 2021

Published: 2 May 2021

Publisher's Note: MDPI stays neutral with regard to jurisdictional claims in published maps and institutional affiliations.

Copyright: (c) 2021 by the authors. Licensee MDPI, Basel, Switzerland. This article is an open access article distributed under the terms and conditions of the Creative Commons Attribution (CC BY) license (https:/ / creativecommons.org/licenses/by/ $4.0 /)$.

\begin{abstract}
Evidence on the association between various dietary constructs and obesity risk is limited. This study aims to investigate the longitudinal relationship between different diet indices and dietary patterns with the risk of obesity. Non-obese participants $(n=787)$ in the North West Adelaide Health Study were followed from 2010 to 2015 . The dietary inflammatory index (DII ${ }^{\circledR}$ ), plant-based dietary index (PDI) and factor-derived dietary pattern scores were computed based on food frequency questionnaire data. We found the incidence of obesity was $7.62 \%$ at the 5-year follow up. In the adjusted model, results from multivariable log-binomial logistic regression showed that a prudent dietary pattern $\left(\mathrm{RR}_{\mathrm{Q} 5}\right.$ vs. $\left.\mathrm{Q} 1=0.38 ; 95 \% \mathrm{CI}: 0.15-0.96\right)$, healthy PDI $(\mathrm{RR}=0.31 ; 95 \% \mathrm{CI}: 0.12-0.77)$ and overall PDI ( $R R=0.56 ; 95 \%$ CI: 0.23-1.33) were inversely associated with obesity risk. Conversely, the DII (RR $=1.59 ; 95 \% \mathrm{CI}: 0.72-3.50)$, a Western dietary pattern $(\mathrm{RR}=2.16$; 95\% CI: $0.76-6.08)$ and unhealthy PDI (RR = 1.94; 95\% CI: 0.81-4.66) were associated with increased risk of obesity. Based on the cubic spline analysis, the association between an unhealthy PDI or diet quality with the risk of obesity was non-linear. In conclusion, an anti-inflammatory diet, healthy diet or consumption of healthy plant-based foods were all associated with a lower risk of developing obesity.
\end{abstract}

Keywords: dietary inflammatory index; dietary pattern; plant-based diet; diet quality; obesity; prospective study

\section{Introduction}

Obesity has become a global challenge, with a devastating impact on public health, the economy and climate [1]. In the past four decades, the global prevalence of obesity has rapidly increased. According to the World Health Organization (WHO), 49\% of adults globally were overweight, and 13\% were obese in 2016 [2]. In 2017-2018, 67\% of Australian adults were overweight and 31\% were obese [3]. Furthermore, the escalating global prevalence of obesity begins early in life [4]. If this trend continues, it is predicted that $18 \%$ of men, over $21 \%$ of women, and 124 million children and adolescents in the global population will be obese in 2025 [5].

Diet is a key modifiable factor in obesity prevention. There are different dietary indices or patterns of overall dietary intake currently available, such as the dietary inflammatory index $\left(\mathrm{DII}^{\circledR}\right)$, dietary quality indices (e.g., prudent and Western diet), and a recently developed plant-based dietary index (PDI). The DII is a literature-based algorithm scoring 
tool, designed to measure the inflammatory potential of a diet [6], while the dietary pattern is an emerging analysis approach meant to evaluate the relationship between diet and disease, which generally categorizes diet into a healthy (prudent) and unhealthy (Western) pattern [7]. Conversely, PDI is a recently developed index with a focus on the intake of plant-based foods [8].

Many studies have examined the association between DII, dietary patterns or PDI with metabolic syndromes [9,10] or chronic diseases such as cardiovascular diseases [11,12], diabetes [12,13] and certain types of cancers [14]. However, evidence on the association between the DII, PDI or dietary patterns and obesity prevention are limited, particularly in Australia. In fact, the existing studies are mainly cross-sectional [15], conducted in specific populations (e.g., specific age groups or sex) $[16,17]$, and assessed each measurement tool independently. Given that food environment and availability could vary across different regions, and the fact that obesity develops gradually over time, understanding the longitudinal relationship between dietary indices, dietary patterns and the risk of obesity becomes important. Therefore, in this study, we aimed to investigate the prospective association between the DII, dietary patterns and intake of plant-based foods with the risk of obesity in the North West Adelaide Health Study (NWAHS) cohort. To our knowledge, this is the first study to examine the longitudinal association between DII, PDI, dietary patterns and obesity risk in Australia.

\section{Materials and Methods}

\subsection{Study Design and Population}

The NWAHS is a longitudinal cohort study representing one-third of the population in South Australia and approximately half of the metropolitan area ( 1.1 million people) [18]. This state has the second highest proportion of elderly residents ( $\geq 65$ years old) among all the Australian states and territories after Tasmania [18,19]. Recruitment details have been described in detail previously [20]. In brief, eligible participants (age $\geq 18$ years old), from northern and western suburbs of Adelaide, South Australia, were randomly selected from the electronic White Page ${ }^{\circledR}$ and recruited using the telephone. Three stages of data collection were conducted in: 1999-2003 (Stage 1), 2004-2006 (Stage 2) and 2008-2010 (Stage 3 ), using a computer-assisted telephone interview (CATI), self-administered questionnaire and clinic examination. In 2015, a follow up study using a self-completed online or postal survey was conducted (NW15).

In this study, we utilised data from Stage 3 and NW15 with a total of 787 participants included for a prospective study examining the association between the DII, dietary pattern or PDI and the risk of obesity (Figure 1). We excluded 177 participants, including participants without total energy intake data $(n=136)$ or if the participants total energy intake was $<800 \mathrm{kcal}$ for men, $<600 \mathrm{kcal}$ for women, and $>4000 \mathrm{kcal}$ for both males and females $(n=41)$. Another 1461 participants were excluded due to lack of BMI data in stage $3(n=90)$ or NW15 $(n=984)$ or were obese at stage $3(n=387)$. We also excluded 75 due to missing values for covariates.

This study was approved by The Human Ethics Research Committee, Queen Elizabeth Hospital, South Australia. All participants provided written informed consent. 


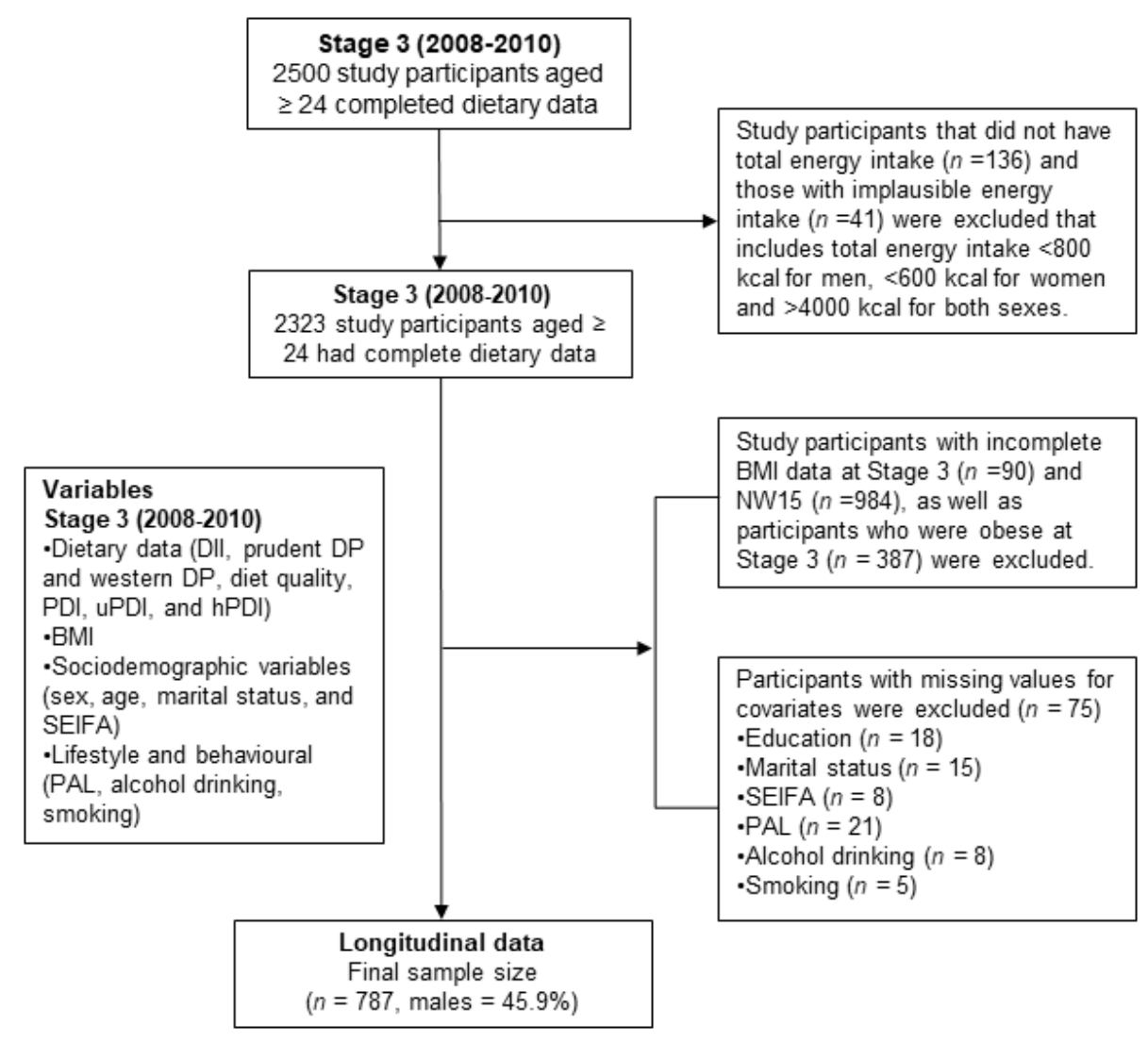

Figure 1. Sampling description of the study participants in the North West Adelaide Health Study (NWAHS). BMI: body mass index; SEIFA: Socio-Economic Indexes for Area; PAL: Physical Level Activity; DII: Dietary Inflammatory Index; DP: dietary pattern; PDI: Plant-based Dietary Index; uPDI: unhealthy Plant-Based Dietary Index; hPDI: healthy Plant-Based Dietary Index.

\subsection{Measures of BMI at Stage 3 and NW15}

Height and weight were measured using standard protocols during the clinic examination in Stage 3, while in NW15, height and weight were self-reported. BMI was computed as weight $(\mathrm{kg}) /$ height $(\mathrm{m})^{2}$ [21]. Participants with BMI $\geq 30 \mathrm{~kg} / \mathrm{m}^{2}$ were categorised as obese and participants with $\mathrm{BMI}<30 \mathrm{~kg} / \mathrm{m}^{2}$ were categorised as non-obese.

\subsection{Dietary Assessment and Analysis}

An assessment of the previous 12 months dietary intake was conducted at Stage 3 using a revised Food Frequency Questionnaire (FFQ), the validated Dietary Questionnaire for Epidemiological Studies Version 3 (DQES-V3.1), developed by Cancer Council Victoria [22]. The questionnaire was self-completed. The data obtained from this questionnaire were used to generate the dietary constructs below:

\subsection{Dietary Inflammatory Index}

The construction of the DII has been described in detail previously [6]. In brief, the DII is a robust literature-based scoring algorithm that compares the inflammatory properties of diets. Calculation was performed by linking to a representative global database from 11 populations in the world to obtain a z-score. The z-score was then converted into a percentile, followed by doubling the value and subtracted by 1 to centre the values. The overall DII score, for each participant, was obtained from the sum of all food parameters and adjusted article scores. The higher the DII value, the more pro-inflammatory the diet and, conversely, the lower the score the more anti-inflammatory the diet.

The DII value in this study was generated by scoring 29 out of 45 food parameters based on their effect on 6 inflammatory markers (IL-1B, IL-4, IL-6, IL-10, TNF- $\alpha$ and C- 
reactive protein). The food parameters included carbohydrate, protein, fat, saturated fatty acids, monounsaturated fatty acids, polyunsaturated fatty acids, cholesterol, trans-fat, alcohol, iron, zinc, thiamine, magnesium, niacin, riboflavin, fibre, omega-3, omega-6, folic acid, $\beta$-carotene, tea, garlic, onions, vitamin A, B6, B12, C, D, and E. The DII value was adjusted to the total energy intake.

\subsection{Dietary Pattern}

We used two dietary patterns, the prudent pattern (healthy diet) and the Western pattern (unhealthy diet), which have been identified previously using principal composite analysis (PCA) [23]. In brief, thirty-nine dietary patterns were constructed based on food groups. A scree plot, an eigenvalue $(>1)$ and interpretability were used to determine two retained factors. Varimax rotation was applied to increase factor interpretability. The sum of factor loading coefficients, standardized by the daily intake of individual food item, was used to calculate factor scores for each participant as well as the retained factors. A KaiserMeyer-Olkin test was used to check for sample adequacy. As participants are unlikely to exclusively follow either a prudent or Western dietary intake pattern, the Western pattern score was subtracted from the prudent pattern score for each participant to generate a value for "diet quality".

\subsection{Plant-Based Dietary Index}

We also developed three plant-based dietary indices, i.e., PDI, healthy PDI (hPDI) and unhealthy PDI (uPDI), using the approach described by Satija et al. [24]. Eighteen food groups were generated to represent healthy and unhealthy plant foods, as well as animal foods (Supplementary Table S1). Healthy and unhealthy plant foods were distinguished based on the existing literature on the association between various foods and chronic diseases. We excluded plant foods that could not be categorized as healthy or unhealthy (e.g., alcoholic drinks). Nonetheless, alcohol intake was adjusted for in multivariable regression analyses. Each food group was then categorized into sex-specific deciles and scored from 1 to 10 positively $(\mathrm{Q} 1=1 \rightarrow \mathrm{Q} 10=10)$ or vice versa $(\mathrm{Q} 1=10 \rightarrow \mathrm{Q} 10=1)$. For the PDI, we allocated positive scores for healthy and unhealthy plant foods while reverse scores were allocated for animal foods. For the hPDI, healthy plant foods were allocated positive scores while less healthy plant foods and animal foods were given reverse scores. To create the uPDI, we gave positive scores to less healthy plant foods and allocated reverse scores for healthy plant foods and animal foods. The sum of the food scores were used to acquire PDI, uPDI and hPDI values that ranged from 18 to 180. A higher index represents more plant-based and less animal-based diet.

\subsection{Assessment of Covariates}

Potential behavioural and socioeconomic confounders that may be associated with diet factors and the risk of obesity were identified. Detailed criteria to determine categories for each covariate have been described previously [20]. Smoking status was categorised into non-smoker, ex-smoker, and current smoker. Alcohol risk was categorised into nondrinkers and no risk, low risk, intermediate risk, high to very high risk, and incomplete information based on the 1989 National Heart Foundation Risk Factor Prevalence study classification formula [25]. Physical activity levels (PAL) were assessed using the Active Australia Survey and the results were categorised into no activity, insufficient activity, and sufficient activity [26].

Socioeconomic status was collected based on the Socio-Economic Index for Areas (SEIFA), developed by the Australian Bureau of Statistics, which ranks areas in Australia according to relative socioeconomic advantage and disadvantage based on five-yearly census data [27]. In this study, we used the Index of Relative Social Disadvantage (IRSD) and divided the determined value into quintiles where the lowest represents the greatest disadvantage. Participants' marital status was categorised into married or living with partner, separated/divorced, widowed, never married, or not stated. 


\subsection{Statistical Analyses}

Descriptive analysis of sociodemographic and lifestyle characteristics was conducted across the factor quintiles. Mean values and standard deviations were calculated for continuous and normally distributed variables. Proportions were calculated for categorical variables. Chi-square tests for categorical variables and ANOVA were used to identify significant differences across different levels of dietary pattern scores. The $p$-value for trend was determined using quintiles as continuous variables. Generalized linear model with binomial family and log link was used to estimate the risk ratio used to assess the association between dietary patterns and obesity. For the dietary patterns, two regression models were developed. Model one was adjusted for age and sex. Model two was additionally adjusted for marital status, SEIFA, smoking status, alcohol risk and PAL. The trend of association was assessed using the quintiles of dietary patterns as continuous variables. A restricted cubic spline regression analysis was performed to determine the dose-response relationship between dietary constructs and the risk of obesity. All analyses were conducted using STATA/SE version 16 (Stata, StataCorp LP, College Station, TX, USA).

\section{Results}

In this study, 787 non-obese participants of the NWAHS cohort from a total of 2500 subjects at Stage 3 were included (Figure 1). A total of 1326 (53\%) participants were excluded because: (1) there was invalid baseline energy intake $(n=177)$; (2) there were missing values for BMI at Stage 3 or NW15 ( $n=1074)$; (3) the participants were obese at Stage $3(n=387)$; or (4) there were missing values of covariates $(n=75)$. The mean age of participants was 58.7 years (SD 12.9) and $45.9 \%$ were men. The mean BMI at baseline was $25.6 \mathrm{~kg} / \mathrm{m}^{2}$ (SD 2.7) and the incidence of obesity was $7.62 \%$ at the 5 -year follow up.

Characteristics of the participants at baseline according to the extreme quintiles of DII, diet quality, PDI, hPDI and uPDI are shown in Table 1. The remaining data are provided in Supplementary Tables S2 and S3, respectively. The overall mean DII score of the population was 1.43 (1.36). Diet quality, prudent pattern, PDI and hPDI were inversely associated with the DII, whereas the Western pattern and uPDI were positively associated with the DII. Based on BMI, trends for all diet factors were significant. The prudent pattern, PDI and hPDI were positively associated with diet quality. Conversely, an inverse association was observed between diet quality with the Western pattern and uPDI. No significant trend was observed between quintiles of diet indices and SEIFA. However, around half of the participants were in the low-income group and did not engage in sufficient physical activity. 
Table 1. Baseline characteristics of participants based on the highest and lowest quintiles of DII, diet quality, PDI, uPDI and hPDI.

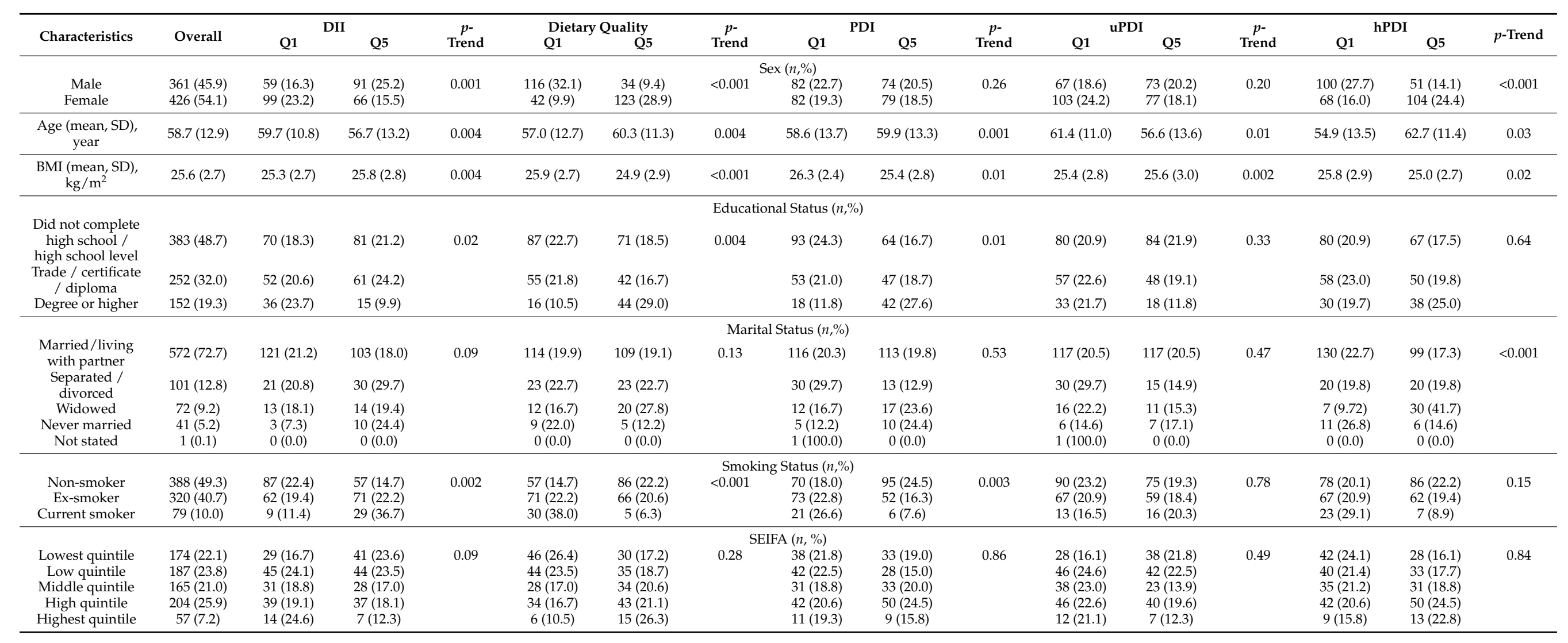


Table 1. Cont.

\begin{tabular}{|c|c|c|c|c|c|c|c|c|c|c|c|c|c|c|c|c|}
\hline \multirow{2}{*}{ Characteristics } & \multirow{2}{*}{ Overall } & \multicolumn{2}{|c|}{ DII } & \multirow{2}{*}{$\begin{array}{c}p- \\
\text { Trend }\end{array}$} & \multicolumn{2}{|c|}{ Dietary Quality } & \multirow{2}{*}{$\begin{array}{c}p- \\
\text { Trend }\end{array}$} & \multicolumn{2}{|c|}{ PDI } & \multirow{2}{*}{$\begin{array}{c}p- \\
\text { Trend }\end{array}$} & \multicolumn{2}{|c|}{ uPDI } & \multirow{2}{*}{$\begin{array}{c}p- \\
\text { Trend }\end{array}$} & \multicolumn{2}{|c|}{ hPDI } & \multirow{2}{*}{$p$-Trend } \\
\hline & & Q1 & Q5 & & Q1 & Q5 & & Q1 & Q5 & & Q1 & Q5 & & Q1 & Q5 & \\
\hline \multicolumn{17}{|c|}{ Alcohol Risk $(n, \%)$} \\
\hline $\begin{array}{l}\text { Non-drinkers } \\
\text { and no risk }\end{array}$ & $377(47.9)$ & $72(19.1)$ & 72 (19.1) & 0.30 & $94(24.9)$ & $57(15.1)$ & $<0.001$ & $68(18.0)$ & $82(21.8)$ & 0.16 & $76(20.2)$ & $82(21.8)$ & 0.48 & $86(22.8)$ & 73 (19.4) & 0.91 \\
\hline $\begin{array}{l}\text { Low risk } \\
\text { Intermediate risk }\end{array}$ & $\begin{array}{c}318(40.4) \\
20(2.5)\end{array}$ & $\begin{array}{l}71(22.3) \\
3(15.0)\end{array}$ & $\begin{array}{l}58(18.2) \\
5(25.0)\end{array}$ & & $\begin{array}{l}35(11.0) \\
10(50.0)\end{array}$ & $\begin{array}{l}84(26.4) \\
2(10.0)\end{array}$ & & $\begin{array}{c}66(20.8) \\
9(45.0)\end{array}$ & $\begin{array}{c}59(18.6) \\
1(5.0)\end{array}$ & & $\begin{array}{c}74(23.3) \\
4(20.0)\end{array}$ & $\begin{array}{l}49(15.4) \\
2(10.0)\end{array}$ & & $\begin{array}{c}60(18.9) \\
4(20.0)\end{array}$ & $\begin{array}{c}65(20.4) \\
2(10.0)\end{array}$ & \\
\hline $\begin{array}{l}\text { High to very high } \\
\text { risk }\end{array}$ & $8(1.0)$ & $0(0.0)$ & $2(25.0)$ & & $3(37.5)$ & $0(0.0)$ & & $3(37.5)$ & $0(0.0)$ & & $2(25.0)$ & $3(37.5)$ & & $2(25.0)$ & $1(12.5)$ & \\
\hline $\begin{array}{l}\text { Incomplete } \\
\text { information }\end{array}$ & $64(8.1)$ & $12(18.8)$ & $20(31.3)$ & & $16(25.0)$ & $14(21.9)$ & & $18(28.1)$ & $11(17.2)$ & & $14(21.9)$ & $14(21.9)$ & & $16(25.0)$ & $14(21.9)$ & \\
\hline \multicolumn{17}{|c|}{ PAL $(n, \%)$} \\
\hline No activity & $101(12.8)$ & $8(7.9)$ & $25(24.6)$ & $<0.001$ & $25(24.8)$ & $7(6.9)$ & $<0.001$ & 27 (26.7) & $13(12.9)$ & 0.32 & $17(16.8)$ & $29(28.7)$ & 0.003 & $21(20.8)$ & $16(15.8)$ & 0.01 \\
\hline $\begin{array}{l}\text { Activity but not } \\
\text { sufficient }\end{array}$ & $322(40.9)$ & $60(18.6)$ & $78(24.2)$ & & $75(23.3)$ & $58(18.0)$ & & $61(18.9)$ & $64(19.9)$ & & $59(18.3)$ & $73(22.7)$ & & $82(25.5)$ & 49 (15.2) & \\
\hline Sufficient activity & $364(46.3)$ & $90(24.7)$ & $54(14.5)$ & & $58(15.9)$ & $92(25.3)$ & & $76(20.9)$ & 76 (20.9) & & $94(25.8)$ & $48(13.2)$ & & $65(17.9)$ & $90(24.7)$ & \\
\hline DII (mean, SD) & $\begin{array}{l}-1.43 \\
(1.36) \\
\end{array}$ & & & & $\begin{array}{l}-0.03 \\
(1.25) \\
\end{array}$ & $\begin{array}{l}-2.64 \\
(0.82) \\
\end{array}$ & 0.43 & $\begin{array}{l}-0.64 \\
(1.42) \\
\end{array}$ & $\begin{array}{l}-2.24 \\
(0.99) \\
\end{array}$ & 0.18 & $\begin{array}{l}-2.11 \\
(1.06) \\
\end{array}$ & $\begin{array}{l}-0.57 \\
(1.50) \\
\end{array}$ & 0.15 & $\begin{array}{l}-0.30 \\
(1.34) \\
\end{array}$ & $\begin{array}{l}-2.27 \\
(1.05) \\
\end{array}$ & 0.21 \\
\hline $\begin{array}{l}\text { Prudent DP } \\
\text { (mean, SD) }\end{array}$ & $0.13(1.02)$ & $1.11(0.97)$ & $\begin{array}{l}-0.77 \\
(0.70) \\
\end{array}$ & 0.39 & $\begin{array}{l}-0.78 \\
(0.70) \\
\end{array}$ & $1.37(0.83)$ & 0.40 & $\begin{array}{l}-0.66 \\
(0.73) \\
\end{array}$ & $0.92(0.92)$ & 0.30 & $1.05(0.99)$ & $\begin{array}{l}-0.71 \\
(0.77) \\
\end{array}$ & 0.33 & $\begin{array}{l}-0.44 \\
(0.88) \\
\end{array}$ & $0.77(1.11)$ & 0.14 \\
\hline $\begin{array}{l}\text { Western DP } \\
(\text { mean, SD) }\end{array}$ & $\begin{array}{l}-0.06 \\
(0.93)\end{array}$ & $\begin{array}{l}-0.46 \\
(0.79)\end{array}$ & $0.38(1.05)$ & 0.10 & $1.02(0.90)$ & $\begin{array}{l}-0.75 \\
(0.63)\end{array}$ & 0.30 & $\begin{array}{l}-0.19 \\
(1.05)\end{array}$ & $0.17(0.91)$ & 0.01 & $\begin{array}{l}-0.03 \\
(0.93)\end{array}$ & $\begin{array}{l}-0.14 \\
(0.86)\end{array}$ & $<0.001$ & $0.69(0.97)$ & $\begin{array}{l}-0.67 \\
(0.70)\end{array}$ & 0.25 \\
\hline $\begin{array}{l}\text { Dietary quality } \\
\text { (mean, SD) }\end{array}$ & $0.18(1.43)$ & $1.56(1.12)$ & $\begin{array}{l}-1.15 \\
(1.30) \\
\end{array}$ & 0.42 & & & & $\begin{array}{l}-0.47 \\
(1.43)\end{array}$ & $0.75(1.36)$ & 0.10 & $1.09(1.37)$ & $\begin{array}{l}-0.56 \\
(1.23)\end{array}$ & 0.15 & $\begin{array}{l}-1.12 \\
(1.30) \\
\end{array}$ & $1.44(1.18)$ & 0.35 \\
\hline PDI (mean, SD) & $\begin{array}{l}101.8 \\
(12.8) \\
\end{array}$ & $\begin{array}{l}108.9 \\
(12.5) \\
\end{array}$ & 91.7 (10.6) & 0.19 & $95.6(12.1)$ & $\begin{array}{l}108.3 \\
(12.1) \\
\end{array}$ & 0.095 & & & & $\begin{array}{l}104.1 \\
(11.6) \\
\end{array}$ & $98.5(12.5)$ & 0.02 & $94.0(10.9)$ & $\begin{array}{l}109.5 \\
(12.5) \\
\end{array}$ & 0.14 \\
\hline uPDI (mean, SD) & $99.8(14.3)$ & $92.3(12.9)$ & $\begin{array}{l}108.4 \\
(13.4) \\
\end{array}$ & 0.14 & $\begin{array}{l}107.1 \\
(14.4) \\
\end{array}$ & $90.4(11.5)$ & 0.17 & $\begin{array}{l}101.9 \\
(13.7) \\
\end{array}$ & $97.7(12.6)$ & 0.02 & & & & $\begin{array}{l}107.8 \\
(14.3) \\
\end{array}$ & $91.8(12.1)$ & 0.14 \\
\hline hPDI (Mean, SD) & $\begin{array}{l}103.1 \\
(14.7)\end{array}$ & $\begin{array}{l}113.9 \\
(12.5)\end{array}$ & $91.7(14.0)$ & 0.26 & $88.3(12.1)$ & $\begin{array}{l}116.0 \\
(12.6)\end{array}$ & 0.39 & $95.9(14.9)$ & $\begin{array}{l}112.1 \\
(12.5)\end{array}$ & 0.15 & $\begin{array}{l}110.4 \\
(14.4)\end{array}$ & $94.5(14.1)$ & 0.14 & & & \\
\hline
\end{tabular}

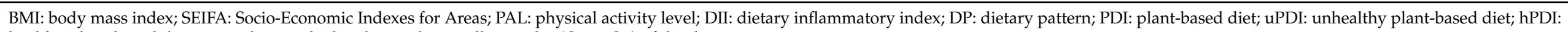
healthy plant-based diet. $p$-trend was calculated considering all quartiles (Q1 to Q5) of the dietary constructs. 
3.1. Anti-Inflammatory Diet, Prudent Pattern, and hPDI Were Inversely Associated with a Lower Risk of Obesity

In model 2, a significant inverse trend was found between prudent dietary pattern (RRQ5VsQ1 = 0.38; 95\% CI: 0.15-0.96); $p=0.013)$, diet quality (RRQ5VsQ1 = 0.23; 95\% CI: 0.08-0.66); $p=0.006$ ), and hPDI (RRQ5VsQ1 = 0.31; 95\% CI: 0.12-0.77); $p=0.006$ ) with the risk of obesity (Table 2). PDI (RRQ5 vs. Q1 $=0.56 ; 95 \%$ CI: $0.23-1.33$ ); $p=0.19$ ) also showed an association with a reduced risk of obesity. For the DII, a more anti-inflammatory $\operatorname{diet}(\mathrm{RRQ} 2$ vs. Q1 $=0.58$; 95\% CI: 0.20-1.68); $p=0.06$ ) was associated with a lower risk of obesity. Conversely, the higher quintiles, representing a more pro-inflammatory diet, were associated with a higher risk of obesity. In addition, diet quality displayed a stronger association with a lower risk of obesity compared to other diet factors.

Table 2. Multivariable adjusted models (95\% confidence intervals) for the risk of obesity.

\begin{tabular}{|c|c|c|c|c|c|c|}
\hline \multirow{2}{*}{ Model } & \multicolumn{5}{|c|}{ Relative Risk (95\% CI) } & \multirow{2}{*}{$p$-Trend } \\
\hline & Q1 & Q2 & Q3 & Q4 & Q5 & \\
\hline \multicolumn{7}{|c|}{ Dietary inflammatory index } \\
\hline Model 1 & 1.00 & $\begin{array}{c}0.56 \\
(0.19-1.62)\end{array}$ & $\begin{array}{c}1.52 \\
(0.68-3.41)\end{array}$ & $\begin{array}{c}1.62 \\
(0.73-3.61)\end{array}$ & $\begin{array}{c}1.78 \\
(0.81-3.91)\end{array}$ & 0.03 \\
\hline Model 2 & 1.00 & $\begin{array}{c}0.58 \\
(0.20-1.68)\end{array}$ & $\begin{array}{c}1.64 \\
(0.73-3.68)\end{array}$ & $\begin{array}{c}1.72 \\
(0.78-3.81)\end{array}$ & $\begin{array}{c}1.59 \\
(0.72-3.50)\end{array}$ & 0.06 \\
\hline \multicolumn{7}{|c|}{ Prudent pattern } \\
\hline Model 1 & 1.00 & $\begin{array}{c}0.70 \\
(0.37-1.33)\end{array}$ & $\begin{array}{c}0.55 \\
(0.30-1.11)\end{array}$ & $\begin{array}{c}0.34 \\
(0.15-0.79)\end{array}$ & $\begin{array}{c}0.36 \\
(0.16-0.83)\end{array}$ & 0.002 \\
\hline Model $2 *$ & 1.00 & $\begin{array}{c}0.75 \\
(0.39-1.43)\end{array}$ & $\begin{array}{c}0.58 \\
(0.28-1.21)\end{array}$ & $\begin{array}{c}0.39 \\
(0.16-0.94)\end{array}$ & $\begin{array}{c}0.38 \\
(0.15-0.96)\end{array}$ & 0.01 \\
\hline \multicolumn{7}{|c|}{ Western pattern } \\
\hline Model 1 & 1.00 & $\begin{array}{c}0.96 \\
(0.43-2.16)\end{array}$ & $\begin{array}{c}1.14 \\
(0.52-2.47)\end{array}$ & $\begin{array}{c}0.82 \\
(0.35-1.92)\end{array}$ & $\begin{array}{c}1.13 \\
(0.51-2.53)\end{array}$ & 0.87 \\
\hline Model $2 *$ & 1.00 & $\begin{array}{c}1.36 \\
(0.59-3.12)\end{array}$ & $\begin{array}{c}1.77 \\
(0.77-4.07)\end{array}$ & $\begin{array}{c}1.57 \\
(0.59-4.16)\end{array}$ & $\begin{array}{c}2.16 \\
(0.76-6.08)\end{array}$ & 0.17 \\
\hline Model 1 & 1.00 & $\begin{array}{c}0.72 \\
(0.37-1.37)\end{array}$ & $\begin{array}{c}\text { Diet qualit } \\
0.46 \\
(0.21-0.99)\end{array}$ & $\begin{array}{c}0.62 \\
(0.30-1.26)\end{array}$ & $\begin{array}{c}0.26 \\
(0.10-0.70)\end{array}$ & 0.007 \\
\hline Model $2 *$ & 1.00 & $\begin{array}{c}0.70 \\
(0.36-1.35) \\
\end{array}$ & $\begin{array}{c}0.40 \\
(0.17-0.90) \\
\end{array}$ & $\begin{array}{c}0.54 \\
(0.25-1.19) \\
\end{array}$ & $\begin{array}{c}0.23 \\
(0.08-0.66)\end{array}$ & 0.006 \\
\hline \multicolumn{7}{|c|}{ Plant-based dietary index } \\
\hline Model 1 & 1.00 & $\begin{array}{c}0.76 \\
(0.38-1.51)\end{array}$ & $\begin{array}{c}0.84 \\
(0.42-1.67)\end{array}$ & $\begin{array}{c}0.65 \\
(0.31-1.38)\end{array}$ & $\begin{array}{c}0.45 \\
(0.19-1.05)\end{array}$ & 0.07 \\
\hline Model 2 & 1.00 & $\begin{array}{c}0.75 \\
(0.37-1.50) \\
\end{array}$ & $\begin{array}{c}0.87 \\
(0.44-1.72)\end{array}$ & $\begin{array}{c}0.68 \\
(0.32-1.45)\end{array}$ & $\begin{array}{c}0.56 \\
(0.23-1.33)\end{array}$ & 0.19 \\
\hline \multicolumn{7}{|c|}{ Healthy plant-based dietary index } \\
\hline Model 1 & 1.00 & $\begin{array}{c}0.35 \\
(0.16-0.77)\end{array}$ & $\begin{array}{c}0.73 \\
(0.38-1.39)\end{array}$ & $\begin{array}{c}0.48 \\
(0.23-0.99)\end{array}$ & $\begin{array}{c}0.30 \\
(0.12-0.74)\end{array}$ & 0.02 \\
\hline Model 2 & 1.00 & $\begin{array}{c}0.367 \\
(0.17-0.80) \\
\end{array}$ & $\begin{array}{c}0.67 \\
(0.35-1.29) \\
\end{array}$ & $\begin{array}{c}0.39 \\
(0.19-0.81)\end{array}$ & $\begin{array}{c}0.31 \\
(0.12-0.77) \\
\end{array}$ & 0.006 \\
\hline \multicolumn{7}{|c|}{ Unhealthy plant-based dietary index } \\
\hline Model 1 & 1.00 & $\begin{array}{c}1.30 \\
(0.52-3.21)\end{array}$ & $\begin{array}{c}1.92 \\
(0.84-4.42)\end{array}$ & $\begin{array}{c}1.88 \\
(0.81-4.37)\end{array}$ & $\begin{array}{c}1.74 \\
(0.74-4.11)\end{array}$ & 0.13 \\
\hline Model 2 & 1.00 & $\begin{array}{c}1.33 \\
(0.54-3.28)\end{array}$ & $\begin{array}{c}1.95 \\
(0.85-4.49)\end{array}$ & $\begin{array}{c}1.87 \\
(0.81-4.33)\end{array}$ & $\begin{array}{c}1.94 \\
(0.81-4.66)\end{array}$ & 0.09 \\
\hline
\end{tabular}

Model 1 was adjusted for sex and age. Model 2 was additionally adjusted for educational status, marital status, SEIFA, smoking status, alcohol risk, and PAL. * was additionally adjusted for total energy intake. Total energy intake was adjusted in the dietary constructs for the dietary inflammatory index, plant-based dietary index, healthy and unhealthy plant-based dietary index. Statistically significant values $(p<0.05)$ are indicated in bold. 


\subsection{Western Dietary Pattern and uPDI Were Associated with a Higher Risk of Obesity}

A Western pattern (RRQ5 vs. Q1 $=1.13$; 95\% CI: 0.51-2.53); $p=0.872$ ) and uPDI (RRQ5 vs. $\mathrm{Q} 1=1.74 ; 95 \%$ CI: $0.74-4.11$ ); $p=0.134$ ) were associated with the risk of obesity (Model 1 ) although no significant trend was obtained. After adjustment for other covariates (Model 2), the trend was unchanged; Western pattern (RRQ5 vs. Q1 $=2.16$; 95\% CI: 0.76-6.08); $p=0.167$ ) and uPDI (RRQ5 vs. Q1 = 1.94; 95\% CI: 0.81-4.66); $p=0.088$ ) (Table 2). However, the association between Western dietary pattern and the risk of obesity was stronger after adjustment for covariates.

\subsection{Diet and Risk of Obesity Dose-Response Relationship}

We found a significant non-linear association between diet quality and an unhealthy plant-based diet and the risk of obesity ( $p$ value non-linear $<0.05$ ) (Figure 2 ).
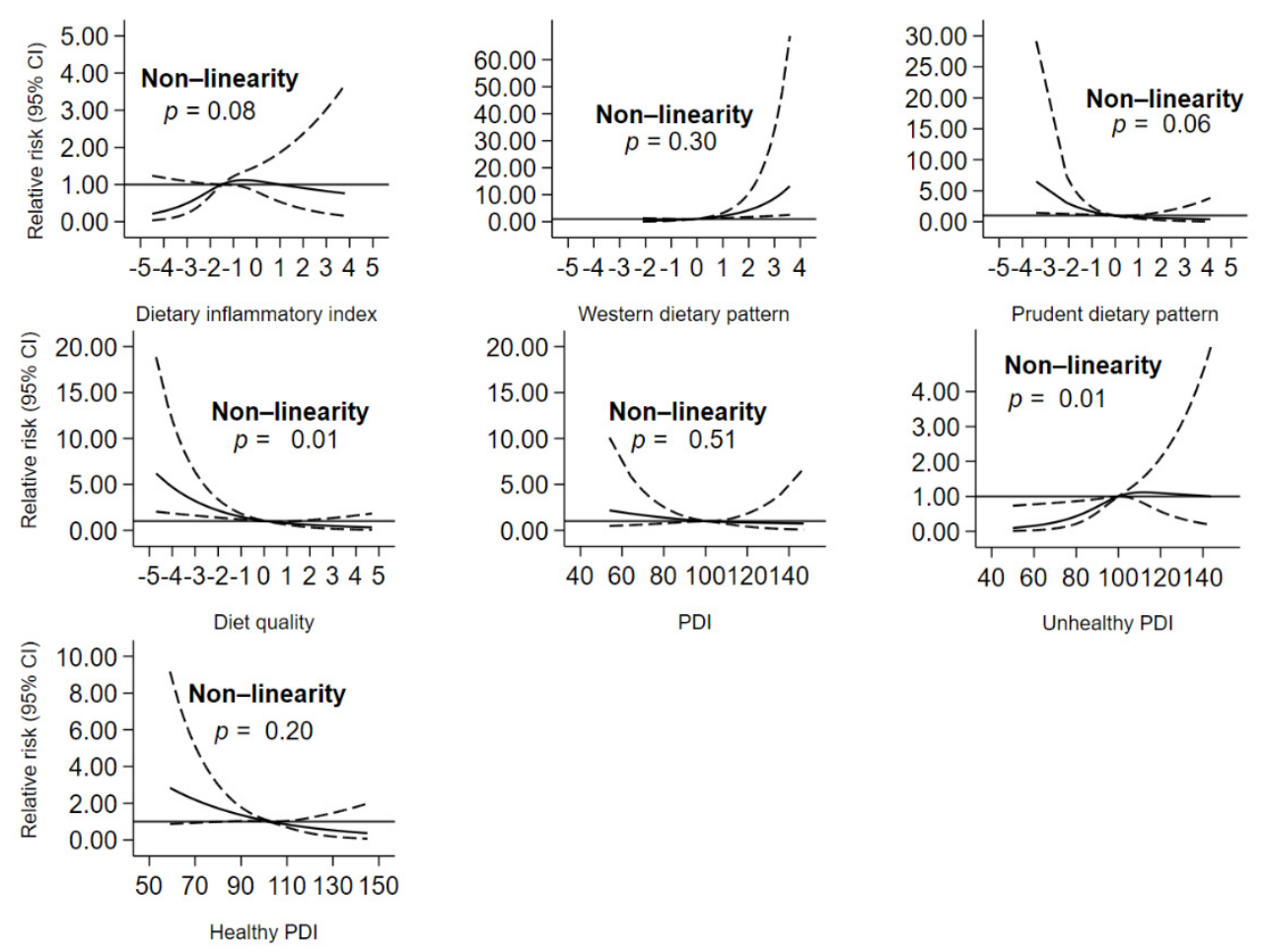

Figure 2. Dose-response relationship curve showing the relationship between dietary constructs and the risk of obesity. PDI: Plant-Based Dietary Index.

\section{Discussion}

To the best of our knowledge, this study is the first to investigate the association between a number of dietary indices and patterns (both a priori and a posteriori dietary data analysis methods) with incidence of obesity in a community-based cohort. Our study found that the incidence of obesity, in the NWAHS cohort, between 2010 and 2015 was $7.62 \%$. After adjustment for potential confounders, an anti-inflammatory diet (a lower DII score), diet quality, prudent dietary pattern, overall PDI and hPDI were associated with a lower risk of obesity. Conversely, a pro-inflammatory diet (a higher DII score), Western dietary pattern, and uPDI were related to a higher risk of obesity. The association between diet quality and unhealthy PDI with the risk of obesity were non-linear.

\subsection{DII and the Development of Obesity}

Several studies have assessed the relationship between the inflammatory potential of diet and overweight or obesity. A higher DII score, indicating a more pro-inflammatory diet, has been associated with a higher BMI, waist circumference, waist-height ratio, and increased risk of cardiovascular diseases and cancer [15,28-30]. A cross-sectional study, 
in the Cohort of Universities of Minas Gerais, also displayed an increased prevalence of obesity with a higher DII score [31]. Furthermore, a longitudinal study in a Mediterranean cohort also showed that a greater DII score was associated with an increased average yearly weight change and the incidence of overweight and obesity over 10 years follow up [32]. Our findings are in alignment with these previous studies in confirming that a higher DII score was associated with an increased risk of obesity while a lower DII score was related to a lower risk of obesity.

\subsection{Dietary Patterns and the Risk of Obesity}

The current food-based dietary recommendations highlight a healthy diet, characterized by increased intake of fruits and vegetables and reduced consumption of high fat foods, for better health. In agreement with the recommendations, our findings indicate that adherence to a prudent diet was associated with a lower risk of obesity. Outcomes from meta-analyses showed that the prudent dietary pattern was associated with a lower risk of overweight or obesity $[33,34]$. Another study also has shown that a higher adherence to a prudent dietary pattern was related with a lower risk of central obesity, abnormal glucose level and metabolic syndrome [9]. Furthermore, intake of reduced-fat dairy products and high-fibre foods, which is aligned with food groups identified in the prudent dietary pattern in the current cohort [23], was related with a reduced increase in waist circumference in both women and men [35].

Our findings also revealed an association between the Western dietary pattern and the risk of obesity. Although there are inconsistent findings on the relationship between food patterns and BMI or obesity [36,37], the majority of studies have revealed a positive relationship between a Western dietary pattern and the risk of obesity, central obesity, and higher body fat proportion [38,39].

\subsection{Plant-Based Diet and the Risk of Obesity}

Healthy dietary patterns (e.g., Mediterranean, Dietary Approaches to Stop Hypertension (DASH), Nordic, vegan, vegetarian), which emphasize an intake of plant-based foods, have been associated with weight loss [13] and a lower-risk of obesity-related chronic diseases [11]. Our study showed that overall PDI was related to a lower risk ratio of obesity, suggesting that consumption of more plant-based foods and limiting animal-based diets may reduce the risk of obesity. The relationship between adherence to a plant-based diet, or limiting the intake of animal-based foods, with the risk of obesity is still under debate [40,41]. Nevertheless, evidence has shown that increased consumption of animal foods was associated with a greater odds of obesity [38] and adherence to a vegan or vegetarian diet was related to a lower BMI [40]. However, these results were mainly obtained from cross-sectional studies which are prone to information bias [40]. Thus, more prospective studies are required to confirm this relationship.

In addition to the overall PDI, we also examined the association between hPDI or uPDI with the risk of obesity. Our finding showed that uPDI was associated with a greater risk of obesity while an inverse association was observed for hPDI. This suggests a protective effect of healthy plant-based foods against weight gain. Healthy plant-based foods (e.g., whole grains, fruits, vegetables, nuts, legumes, and vegetable oils) were related to lower adiposity and fatty liver content [42] and risk of cardiovascular diseases [8]. Importantly, our results are in agreement with three other prospective cohort studies showing that diets rich in healthy plant-based foods were associated with lower weight gain over four years follow up [24].

\subsection{Potential Mechanisms}

Inflammation is the substrate on which several putative mechanisms can work to increase obesity. Prominent among these is insulin resistance [43]. Although inflammation is often considered a consequence of the obese state, increasing evidence suggest that inflammation may contribute to the development of obesity. For instance, knockout animal 
studies have implicated pro-inflammatory cytokines, such as IL-6 and TNF- $\alpha$, in the development of obesity $[44,45]$. Furthermore, cohort studies in middle-aged and older adults have shown that elevated levels on inflammatory markers, such as inflammationsensitive proteins (i.e., fibrinogen, haptoglobin, alpha1-antitrypsin, orosomucoid, and ceruloplasmin), IL-6, albumin, C-reactive protein (CRP), factor VIIIc, white blood cell count, and platelet count, were associated with a greater risk of future weight gain [46-48].

There are several ways that diet can influence inflammation. First, diet modifies oxidative stress levels in the body, leading to changes in inflammatory status. For instance, intake of a high-fat diet triggers activation of pro-inflammatory pathways, causing oxidative stress that leads into systemic inflammation [49]. On the other hand, intake of fruits and vegetables lowers oxidative stress and subsequently, inflammation [50,51]. Fruits and vegetables are rich in antioxidants, which play a key role in reducing oxidative stress through its antioxidative capacity. Studies have linked high antioxidative scores, measured using oxygen radical absorbance capacity (ORAC), to anti-inflammatory diet [52] and to a reduced level of clinical inflammatory markers, such as IL-6 [53] and CRP [53,54]. Therefore, this may explain how adherence to an anti-inflammatory, healthy and plant-based diet, which are all characterized by an increased intake of fruits and vegetables, reduce the risk of obesity.

Second, diet can alter gut microbiome composition which, in turn, can affect inflammation. The type of diet influences the characteristics of gut microbiota/microbiome [55-57], in particular the balance of pro- and anti-inflammatory gut microbiota population in the gut [58]. The Western diet has been associated with an increased pro-inflammatory potential of gut microbiota [59]. Conversely, the plant-based diet has been linked with producers of short chain fatty acids (SCFA) [60], by-products of gut microbiota that have anti-inflammatory properties [61]. Furthermore, a study has also shown that a lower DII score was associated with anti-inflammatory gut microbiota and reduced inflammatory markers [52,62]. Altogether, this may explain the protective effect of an anti-inflammatory, healthy and plant-based diet towards obesity by preventing inflammation through gut microbiota. Further studies, however, are still required to confirm the current potential mechanisms and to reveal other possible mechanisms underlying the association between diet, inflammation and obesity.

\subsection{Strengths and Limitations}

There are a number of limitations of this study, including the possibility of errors in self-report of diet using the FFQ and exclusion of certain food groups that are simply left off the food list [63]. However, the FFQ has been widely used to construct DII [32], dietary patterns [23], and PDI [8] for cohort studies. Thus, this validating evidence provides some confidence about the reliability of the FFQ to assess overall dietary intake. There are also nutrients and/or foods, such as sodium [64], calcium [65], potassium [66], riboflavin (vitamin B2) [67], and pantothenic acid (vitamin B5) [68], which were not incorporated in the DII that may have impacted on inflammation or the risk of obesity. However, none of these parameters had sufficient evidence to warrant inclusion in the DII formulation. In addition, the BMI at NW15 was calculated based on self-reported height and weight data. Although the self-reported method has been previously validated, this may have underestimated the risk of obesity as an outcome [69]. Furthermore, the sample size in this study was relatively small, which may have contributed to less precise estimates (wider confidence intervals, which included the null value) despite large effect sizes (point estimates). A strength of this study is that it provides comprehensive analysis using multiple dietary indices and a posteriori dietary patterns to determine the longitudinal relationship between diet and the risk of obesity.

\subsection{Significance}

Results from this study support the notion that diet is pivotal in obesity prevention, where the intake of an anti-inflammatory diet and healthy plant-based food, as well as 
following a healthy dietary pattern, may protect individuals against obesity. This may contribute to improved dietary recommendations and could increase public awareness to adhere to a healthy diet, particularly among low-income individuals and those with insufficient physical activity. Future cohort studies involving a larger number of participants and a longer follow up would be required to confirm this longitudinal association.

\section{Conclusions}

Intake of an anti-inflammatory diet, healthy diet and healthy plant-based foods was associated with a lower risk of obesity. Public health messages should target low-income individuals and those with insufficient physical activity with messaging to increase adherence to plant-based, anti-inflammatory diets and increase physical activity [70,71].

Supplementary Materials: The following are available online at https:/ / www.mdpi.com/article / 10.3390/nu13051536/s1, Table S1: Food items components for the overall PDI, uPDI and hPDI., Table S2: Baseline characteristics of participants based on quintiles of prudent and Western dietary pattern, Table S3: Baseline characteristics of participants based on quintiles 2-4 of DII, diet quality, PDI, uPDI and hPDI.

Author Contributions: Conceptualization, Y.B.W., A.J.P., T.K.G. and Y.A.M.; methodology, Y.B.W., N.S., J.R.H., A.J.P., T.K.G., and Y.A.M.; formal analysis, Y.B.W. and Y.A.M.; data curation, Y.B.W. and Y.A.M.; writing—original draft preparation, Y.B.W.; writing—review and editing, A.J.P., T.K.G., N.S., J.R.H. and Y.A.M.; supervision, A.J.P., T.K.G., and Y.A.M. All authors have read and agreed to the published version of the manuscript.

Funding: This research received no external funding.

Institutional Review Board Statement: The study was approved by The Human Ethics Research Committee, Queen Elizabeth Hospital, South Australia.

Informed Consent Statement: Informed consent was obtained from all subjects involved in the study.

Data Availability Statement: The data presented in this study are available on request from the North West Adelaide Health Study Chief Investigators. The data are not publicly available as this is an on going cohort study.

Acknowledgments: We would like to thank the North West Adelaide Health Study (NWAHS) participants and members of the study team for their substantial contributions in this study. We also acknowledge the University of Adelaide, the South Australian Department of Health and Wellbeing and the South Australian Government through Premier's Science and Research Fund who have been generously funded parts of the NWAHS project. Y.B.W. is supported by an Australia Awards Scholarship from The Department of Foreign Affairs and Trade, The Government of Australia.

Conflicts of Interest: The authors declare no conflict of interest.

Disclosure: James R. Hébert owns controlling interest in Connecting Health Innovations LLC (CHI), a company that has licensed the right to his invention of the dietary inflammatory index $\left(\mathrm{DII}{ }^{\circledR}\right)$ from the University of South Carolina in order to develop computer and smart phone applications for patient counselling and dietary intervention in clinical settings. Nitin Shivappa is an employee of $\mathrm{CHI}$. The subject matter of this paper will not have any direct bearing on that work, nor has that activity exerted any influence on this project.

\section{References}

1. Swinburn, B.A.; Kraak, V.I.; Allender, S.; Atkins, V.J.; Baker, P.I.; Bogard, J.R.; Brinsden, H.; Calvillo, A.; De Schutter, O.; Devarajan, R.; et al. The global syndemic of obesity, undernutrition, and climate change: The lancet commission report. Lancet 2019, 393, 791-846. [CrossRef]

2. WHO. World Health Statistics 2019: Monitoring Health for the Sdgs, Sustainable Development Goals; World Health Organization: Geneva, Switzerland, 2019.

3. ABS. 4364.0.55.001-National Health Survey: First Results, 2017-2018; Australian Bureau of Statistics: Canberra, Australia, 2018.

4. NCD-RisC. Trends in adult body-mass index in 200 countries from 1975 to 2014: A pooled analysis of 1698 population-based measurement studies with $19 \cdot 2$ million participants. Lancet 2016, 387, 1377-1396. [CrossRef] 
5. Afshin, A.; Forouzanfar, M.H.; Reitsma, M.B.; Sur, P.; Estep, K.; Lee, A.; Marczak, L.; Mokdad, A.H.; Moradi-Lakeh, M.; Naghavi, M.; et al. Health effects of overweight and obesity in 195 countries over 25 years. N. Engl. J. Med. 2017, 377, 13-27. [CrossRef] [PubMed]

6. Shivappa, N.; Steck, S.E.; Hurley, T.G.; Hussey, J.R.; Hebert, J.R. Designing and developing a literature-derived, population-based dietary inflammatory index. Public Health Nutr. 2014, 17, 1689-1696. [CrossRef] [PubMed]

7. Hu, F.B. Dietary pattern analysis: A new direction in nutritional epidemiology. Curr. Opin. Lipidol. 2002, 13, 3-9. [CrossRef]

8. Satija, A.; Bhupathiraju, S.N.; Spiegelman, D.; Chiuve, S.E.; Manson, J.E.; Willett, W.; Rexrode, K.M.; Rimm, E.B.; Hu, F.B. Healthful and unhealthful plant-based diets and the risk of coronary heart disease in U.S. Adults. J. Am. Coll. Cardiol. 2017, 70, 411-422. [CrossRef] [PubMed]

9. Agodi, A.; Maugeri, A.; Kunzova, S.; Sochor, O.; Bauerova, H.; Kiacova, N.; Barchitta, M.; Vinciguerra, M. Association of dietary patterns with metabolic syndrome: Results from the kardiovize brno 2030 study. Nutrients 2018, 10, 898. [CrossRef]

10. Abdollahzad, H.; Pasdar, Y.; Nachvak, S.M.; Rezaeian, S.; Saber, A.; Nazari, R. The relationship between the dietary inflammatory index and metabolic syndrome in ravansar cohort study. Diabetes Metab. Syndr. Obes. Targets Ther. 2020, 13, 477-487. [CrossRef]

11. Kim, H.; Caulfield, L.E.; Garcia-Larsen, V.; Steffen, L.M.; Coresh, J.; Rebholz, C.M. Plant based diets are associated with a lower risk of incident cardiovascular disease, cardiovascular disease mortality, and cause mortality in a general population of aged adults. J. Am. Heart Assoc. 2019, 8, e012865. [CrossRef]

12. McNaughton, S.A.; Dunstan, D.W.; Ball, K.; Shaw, J.; Crawford, D. Dietary quality is associated with diabetes and cardio-metabolic risk factors. J. Nutr. 2009, 139, 734-742. [CrossRef]

13. Wright, N.; Wilson, L.; Smith, M.; Duncan, B.; McHugh, P. The broad study: A randomised controlled trial using a whole food plant-based diet in the community for obesity, ischaemic heart disease or diabetes. Nutr. Diabetes 2017, 7, e256. [CrossRef] [PubMed]

14. Boden, S.; Myte, R.; Wennberg, M.; Harlid, S.; Johansson, I.; Shivappa, N.; Hebert, J.R.; Van Guelpen, B.; Nilsson, L.M. The inflammatory potential of diet in determining cancer risk; a prospective investigation of two dietary pattern scores. PLoS ONE 2019, 14, e0214551. [CrossRef] [PubMed]

15. Ruiz-Canela, M.; Zazpe, I.; Shivappa, N.; Hebert, J.R.; Sanchez-Tainta, A.; Corella, D.; Salas-Salvado, J.; Fito, M.; LamuelaRaventos, R.M.; Rekondo, J.; et al. Dietary inflammatory index and anthropometric measures of obesity in a population sample at high cardiovascular risk from the predimed (prevencion con dieta mediterranea) trial. Br. J. Nutr. 2015, 113, 984-995. [CrossRef]

16. Vahid, F.; Bourbour, F.; Gholamalizadeh, M.; Shivappa, N.; Hebert, J.R.; Babakhani, K.; Mosavi Jarrahi, A.; Mirzaei Dahka, S.; Doaei, S. A pro-inflammatory diet increases the likelihood of obesity and overweight in adolescent boys: A case-control study. Diabetol. Metab. Syndr. 2020, 12, 29. [CrossRef]

17. Olstad, D.L.; Lamb, K.E.; Thornton, L.E.; McNaughton, S.A.; Crawford, D.A.; Minaker, L.M.; Ball, K. Prospective associations between diet quality and body mass index in disadvantaged women: The resilience for eating and activity despite inequality (readi) study. Int. J. Epidemiol. 2017, 46, 1433-1443. [CrossRef] [PubMed]

18. Grant, J.F.; Taylor, A.W.; Ruffin, R.E.; Wilson, D.H.; Phillips, P.J.; Adams, R.J.; Price, K. Cohort profile: The north west adelaide health study (nwahs). Int. J. Epidemiol. 2009, 38, 1479-1486. [CrossRef]

19. AIHW. Older Australia at a Glance; Cat. no. AGE 87; AIHW: Canberra, Australia, 2018.

20. Grant, J.F.; Chittleborough, C.R.; Taylor, A.W.; Dal Grande, E.; Wilson, D.H.; Phillips, P.J.; Adams, R.J.; Cheek, J.; Price, K.; Gill, T.; et al. The north west adelaide health study: Detailed methods and baseline segmentation of a cohort for selected chronic diseases. Epidemiol. Perspect. Innov. 2006, 3, 4. [CrossRef]

21. Clinical guidelines on the identification, evaluation, and treatment of overweight and obesity in adults: Executive summary. Expert Panel on the Identification, Evaluation, and Treatment of Overweight in Adults. Am J Clin Nutr. 1998, 68, 899-917. [CrossRef]

22. Victoria, C.C. Dietary Questionnaires for Epidemiological Studies. Available online: https://www.cancervic.org.au/research/ epidemiology/nutritional_assessment_services (accessed on 27 November 2020).

23. Shakya, P.R.; Melaku, Y.A.; Page, A.; Gill, T.K. Association between dietary patterns and adult depression symptoms based on principal component analysis, reduced-rank regression and partial least-squares. Clin. Nutr. 2019. [CrossRef]

24. Satija, A.; Malik, V.; Rimm, E.B.; Sacks, F.; Willett, W.; Hu, F.B. Changes in intake of plant-based diets and weight change: Results from 3 prospective cohort studies. Am. J. Clin. Nutr. 2019, 110, 574-582. [CrossRef]

25. AIHW. Risk Factor Prevalence Study: Survey No. 3 1989; AIHW: Canberra, Australia, 1990.

26. Armstrong, T.; Bauman, A.E.; Davies, J. Physical Activity Patterns of Australian Adults: Results of the 1999 National Physical Activity Survey; Australian Institute of Health and Welfare: Canberra, Australia, 2000.

27. ABS. Socio-Economic Indexes for Areas (Seifa); Australian Bureau of Statistics: Canberra, Australia, 2016.

28. Ji, M.; Hong, X.; Chen, M.; Chen, T.; Wang, J.; Zhang, N. Dietary inflammatory index and cardiovascular risk and mortality: A meta-analysis of cohort studies. Medicine 2020, 99, e20303. [CrossRef] [PubMed]

29. Zahedi, H.; Djalalinia, S.; Asayesh, H.; Mansourian, M.; Esmaeili Abdar, Z.; Mahdavi Gorabi, A.; Ansari, H.; Noroozi, M.; Qorbani, M. A higher dietary inflammatory index score is associated with a higher risk of incidence and mortality of cancer: A comprehensive systematic review and meta-analysis. Int. J. Prev. Med. 2020, 11, 15. [CrossRef] [PubMed]

30. Farhangi, M.A.; Vajdi, M. The association between dietary inflammatory index and risk of central obesity in adults: An updated systematic review and meta-analysis. Int. J. Vitam. Nutr. Res. 2020, 1-18. [CrossRef] [PubMed] 
31. Oliveira, T.M.S.; Bressan, J.; Pimenta, A.M.; Martínez-González, M.-Á.; Shivappa, N.; Hébert, J.R.; Hermsdorff, H.H.M. Dietary inflammatory index and prevalence of overweight and obesity in brazilian graduates from the cohort of universities of minas gerais (cume project). Nutrition 2020, 71, 110635. [CrossRef]

32. Ramallal, R.; Toledo, E.; Martinez, J.A.; Shivappa, N.; Hebert, J.R.; Martinez-Gonzalez, M.A.; Ruiz-Canela, M. Inflammatory potential of diet, weight gain, and incidence of overweight/obesity: The sun cohort. Obesity 2017, 25, 997-1005. [CrossRef] [PubMed]

33. Mu, M.; Xu, L.F.; Hu, D.; Wu, J.; Bai, M.J. Dietary patterns and overweight/obesity: A review article. Iran. J. Public Health 2017, 46, 869-876.

34. Livingstone, K.M.; McNaughton, S.A. Diet quality is associated with obesity and hypertension in australian adults: A cross sectional study. BMC Public Health 2016, 16, 1037. [CrossRef]

35. Newby, P.; Muller, D.; Hallfrisch, J.; Andres, R.; Tucker, K.L. Food patterns measured by factor analysis and anthropometric changes in adults. Am. J. Clin. Nutr. 2004, 80, 504-513. [CrossRef]

36. Rezagholizadeh, F.; Djafarian, K.; Khosravi, S.; Shab-Bidar, S. A posteriori healthy dietary patterns may decrease the risk of central obesity: Findings from a systematic review and meta-analysis. Nutr. Res. 2017, 41, 1-13. [CrossRef]

37. Togo, P.; Osler, M.; Sørensen, T.I.A.; Heitmann, B.L. Food intake patterns and body mass index in observational studies. Int. J. Obes. 2001, 25, 1741-1751. [CrossRef]

38. Denova-Gutiérrez, E.; Castañón, S.; Talavera, J.O.; Flores, M.; Macías, N.; Rodríguez-Ramírez, S.; Flores, Y.N.; Salmerón, J. Dietary patterns are associated with different indexes of adiposity and obesity in an urban mexican population. J. Nutr. 2011, 141, 921-927. [CrossRef] [PubMed]

39. Paradis, A.M.; Godin, G.; Pérusse, L.; Vohl, M.C. Associations between dietary patterns and obesity phenotypes. Int. J. Obes. 2009, 33, 1419-1426. [CrossRef]

40. Dinu, M.; Abbate, R.; Gensini, G.F.; Casini, A.; Sofi, F. Vegetarian, vegan diets and multiple health outcomes: A systematic review with meta-analysis of observational studies. Crit. Rev. Food Sci. Nutr. 2017, 57, 3640-3649. [CrossRef] [PubMed]

41. Magkos, F.; Tetens, I.; Bügel, S.G.; Felby, C.; Schacht, S.R.; Hill, J.O.; Ravussin, E.; Astrup, A. A perspective on the transition to plant-based diets: A diet change may attenuate climate change, but can it also attenuate obesity and chronic disease risk? Adv. Nutr. 2019, 11, 1-9. [CrossRef] [PubMed]

42. Ratjen, I.; Morze, J.; Enderle, J.; Both, M.; Borggrefe, J.; Müller, H.-P.; Kassubek, J.; Koch, M.; Lieb, W. Adherence to a plant-based diet in relation to adipose tissue volumes and liver fat content. Am. J. Clin. Nutr. 2020, 112, 354-363. [CrossRef] [PubMed]

43. Kirwan, A.M.; Lenighan, Y.M.; O’Reilly, M.E.; McGillicuddy, F.C.; Roche, H.M. Nutritional modulation of metabolic inflammation. Biochem. Soc. Trans. 2017, 45, 979-985. [CrossRef]

44. Di Gregorio, G.B.; Hensley, L.; Lu, T.; Ranganathan, G.; Kern, P.A. Lipid and carbohydrate metabolism in mice with a targeted mutation in the il-6 gene: Absence of development of age-related obesity. Am. J. Physiol. Endocrinol. Metab. 2004, 287, E182-E187. [CrossRef]

45. Uysal, K.T.; Wiesbrock, S.M.; Marino, M.W.; Hotamisligil, G.S. Protection from obesity-induced insulin resistance in mice lacking tnf-alpha function. Nature 1997, 389, 610-614. [CrossRef]

46. Engström, G.; Hedblad, B.; Stavenow, L.; Lind, P.; Janzon, L.; Lindgärde, F. Inflammation-sensitive plasma proteins are associated with future weight gain. Diabetes 2003, 52, 2097-2101. [CrossRef]

47. Barzilay, J.I.; Forsberg, C.; Heckbert, S.R.; Cushman, M.; Newman, A.B. The association of markers of inflammation with weight change in older adults: The cardiovascular health study. Int. J. Obes. 2006, 30, 1362-1367. [CrossRef]

48. Holz, T.; Thorand, B.; Döring, A.; Schneider, A.; Meisinger, C.; Koenig, W. Markers of inflammation and weight change in middle-aged adults: Results from the prospective monica/kora s3/f3 study. Obesity 2010, 18, 2347-2353. [CrossRef] [PubMed]

49. Duan, Y.; Zeng, L.; Zheng, C.; Song, B.; Li, F.; Kong, X.; Xu, K. Inflammatory links between high fat diets and diseases. Front. Immunol. 2018, 9, 2649. [CrossRef] [PubMed]

50. Holt, E.M.; Steffen, L.M.; Moran, A.; Basu, S.; Steinberger, J.; Ross, J.A.; Hong, C.P.; Sinaiko, A.R. Fruit and vegetable consumption and its relation to markers of inflammation and oxidative stress in adolescents. J. Am. Diet. Assoc. 2009, 109, 414-421. [CrossRef]

51. Åsgård, R.; Rytter, E.; Basu, S.; Abramsson-Zetterberg, L.; Möller, L.; Vessby, B. High intake of fruit and vegetables is related to low oxidative stress and inflammation in a group of patients with type 2 diabetes. Scand. J. Food Nutr. 2007, 51, 149-158. [CrossRef]

52. Ruiz-Saavedra, S.; Salazar, N.; Suárez, A.; de Los Reyes-Gavilán, C.G.; Gueimonde, M.; González, S. Comparison of different dietary indices as predictors of inflammation, oxidative stress and intestinal microbiota in middle-aged and elderly subjects. Nutrients 2020, 12, 3828. [CrossRef]

53. Kim, J.; Lee, J.; Oh, J.H.; Chang, H.J.; Sohn, D.K.; Shin, A.; Kim, J. Circulating interleukin-6 level, dietary antioxidant capacity, and risk of colorectal cancer. Antioxidants 2019, 8, 595. [CrossRef] [PubMed]

54. Kobayashi, S.; Murakami, K.; Sasaki, S.; Uenishi, K.; Yamasaki, M.; Hayabuchi, H.; Goda, T.; Oka, J.; Baba, K.; Ohki, K.; et al. Dietary total antioxidant capacity from different assays in relation to serum c-reactive protein among young Japanese women. Nutr. J. 2012, 11, 91. [CrossRef] [PubMed]

55. Chen, J.; He, X.; Huang, J. Diet effects in gut microbiome and obesity. J. Food Sci. 2014, 79, R442-R451. [CrossRef]

56. Wu, G.D.; Chen, J.; Hoffmann, C.; Bittinger, K.; Chen, Y.-Y.; Keilbaugh, S.A.; Bewtra, M.; Knights, D.; Walters, W.A.; Knight, R.; et al. Linking long-term dietary patterns with gut microbial enterotypes. Science 2011, 334, 105-108. [CrossRef] 
57. Tomova, A.; Bukovsky, I.; Rembert, E.; Yonas, W.; Alwarith, J.; Barnard, N.D.; Kahleova, H. The effects of vegetarian and vegan diets on gut microbiota. Front. Nutr. 2019, 6, 47. [CrossRef]

58. Bolte, L.A.; Vich Vila, A.; Imhann, F.; Collij, V.; Gacesa, R.; Peters, V.; Wijmenga, C.; Kurilshikov, A.; Campmans-Kuijpers, M.J.E.; Fu, J.; et al. Long-term dietary patterns are associated with pro-inflammatory and anti-inflammatory features of the gut microbiome. Gut 2021. [CrossRef] [PubMed]

59. Zinöcker, M.K.; Lindseth, I.A. The western diet-Microbiome-host interaction and its role in metabolic disease. Nutrients 2018, 10, 365. [CrossRef] [PubMed]

60. Hartstra, A.V.; Bouter, K.E.; Bäckhed, F.; Nieuwdorp, M. Insights into the role of the microbiome in obesity and type 2 diabetes. Diabetes Care 2015, 38, 159-165. [CrossRef] [PubMed]

61. Tan, J.; McKenzie, C.; Potamitis, M.; Thorburn, A.N.; Mackay, C.R.; Macia, L. The role of short-chain fatty acids in health and disease. Adv. Immunol. 2014, 121, 91-119. [CrossRef]

62. Zheng, J.; Hoffman, K.L.; Chen, J.S.; Shivappa, N.; Sood, A.; Browman, G.J.; Dirba, D.D.; Hanash, S.; Wei, P.; Hebert, J.R.; et al. Dietary inflammatory potential in relation to the gut microbiome: Results from a cross-sectional study. Br. J. Nutr. 2020, 124, 931-942. [CrossRef] [PubMed]

63. Willett, W. Nutritional Epidemiology; Oxford University Press: Oxford, UK, 2012.

64. Ma, Y.; He, F.J.; MacGregor, G.A. High salt intake: Independent risk factor for obesity? Hypertension 2015, 66, 843-849. [CrossRef]

65. Zhang, F.; Ye, J.; Zhu, X.; Wang, L.; Gao, P.; Shu, G.; Jiang, Q.; Wang, S. Anti-obesity effects of dietary calcium: The evidence and possible mechanisms. Int. J. Mol. Sci. 2019, 20, 3072. [CrossRef]

66. Cai, X.; Li, X.; Fan, W.; Yu, W.; Wang, S.; Li, Z.; Scott, E.M.; Li, X. Potassium and obesity/metabolic syndrome: A systematic review and meta-analysis of the epidemiological evidence. Nutrients 2016, 8, 183. [CrossRef]

67. Mazur-Bialy, A.I.; Pocheć, E. Riboflavin reduces pro-inflammatory activation of adipocyte-macrophage co-culture. Potential application of vitamin b2 enrichment for attenuation of insulin resistance and metabolic syndrome development. Molecules 2016, 21, 1724. [CrossRef] [PubMed]

68. Morris, M.S.; Sakakeeny, L.; Jacques, P.F.; Picciano, M.F.; Selhub, J. Vitamin b-6 intake is inversely related to, and the requirement is affected by, inflammation status. J. Nutr. 2010, 140, 103-110. [CrossRef]

69. Taylor, A.W.; Dal Grande, E.; Gill, T.K.; Chittleborough, C.R.; Wilson, D.H.; Adams, R.J.; Grant, J.F.; Phillips, P.; Appleton, S.; Ruffin, R.E. How valid are self-reported height and weight? A comparison between cati self-report and clinic measurements using a large cohort study. Aust. N. Z. J. Public Health 2006, 30, 238-246. [CrossRef] [PubMed]

70. Ghosh, A.; Charlton, K.E.; Batterham, M.J. Socioeconomic disadvantage and its implications for population health planning of obesity and overweight, using cross-sectional data from general practices from a regional catchment in australia. BMJ Open 2016, 6, e010405. [CrossRef] [PubMed]

71. French, S.A.; Tangney, C.C.; Crane, M.M.; Wang, Y.; Appelhans, B.M. Nutrition quality of food purchases varies by household income: The shopper study. BMC Public Health 2019, 19, 231. [CrossRef] [PubMed] 